\title{
Reversible hydrogenation of the Zintl phases BaGe and BaSn studied by in situ diffraction
}

\author{
Henry Auer ${ }^{1}$, Sebastian Weber ${ }^{1}$, Thomas Christian Hansen ${ }^{2}$, Daniel Maria Többens ${ }^{3}$, Holger Kohlmann ${ }^{*}$ \\ ${ }^{1}$ Institute of Inorganic Chemistry, Leipzig Universtity, Johannisallee 29, 04103 Leipzig, Germany, E-mail: holger.kohlmann@ uni- \\ leipzig.de \\ ${ }^{2}$ Institut Laue-Langevin, 71 Avenue des Martyrs, CS 20156, 38042 Grenoble Cedex 9, France \\ ${ }^{3}$ Helmholtz Zentrum Berlin für Materialien und Energie, Albert-Einstein-Str. 15, 12489 Berlin, Germany
}

Received; accepted

Keywords: Zintl phases, In situ diffraction, Neutron diffraction, Metal hydrides

\begin{abstract}
Hydrogenation products of the Zintl phases AeTt $(A e=$ alkaline earth; $T t=$ tetrel $)$ exhibit hydride anions on interstitial sites as well as hydrogen covalently bound to $T t$ which leads to a reversible hydrogenation at mild conditions. In situ thermal analysis, synchrotron and neutron powder diffraction under hydrogen (deuterium for neutrons) pressure was applied to $\mathrm{BaTt}(\mathrm{Tt}=\mathrm{Ge}, \mathrm{Sn})$. $\mathrm{BaTtH}_{\mathrm{y}}(1<\mathrm{y}<1.67, \gamma$-phases $)$ were formed at $5 \mathrm{MPa}$ hydrogen pressure and elevated temperatures (400 - $450 \mathrm{~K})$. Further heating $(500-550 \mathrm{~K})$ leads to a hydrogen release forming the new phases $\beta-\mathrm{BaGeH}_{0.5}$ (Pnma, $a=$ 1319.5(2) pm, $b=421.46(2) \mathrm{pm}, c=991.54(7) \mathrm{pm})$ and $\alpha-$ $\mathrm{BaSnH}_{0.19}(\mathrm{Cmcm}, a=522.72(6) \mathrm{pm}, b=1293.6(2) \mathrm{pm}, c=$ 463.97(6) pm). Upon cooling the hydrogen rich phases are reformed. Thermal decomposition of $\gamma-\mathrm{BaGeH}_{\mathrm{y}}$ under vacuum leads to $\beta-\mathrm{BaGeH}_{0.5}$ and $\alpha-\mathrm{BaGeH}_{0.13}(\mathrm{Cmcm}, a=$ 503.09(3) pm, $b=1221.5(2) \mathrm{pm}, c=427.38(4) \mathrm{pm})$. At $500 \mathrm{~K}$ the reversible reaction $\alpha-\mathrm{BaGeH}_{0.23}($ vacuum $)=$ $\beta-\mathrm{BaGeH}_{0.5}(0.2 \mathrm{MPa}$ deuterium pressure) is fast and was observed with $10 \mathrm{~s}$ time resolution by in situ neutron diffraction. The phases $\alpha-\mathrm{BaTt} \mathrm{H}_{\mathrm{y}}$ show a pronounced phase width (at least $0.09<\mathrm{y}<0.36$ ). $\beta-\mathrm{BaGeH}_{0.5}$ and the $\gamma-$ phases appear to be line phases. The hydrogen poor ( $\alpha$ - and $\beta$-) phases show a partial occupation of $\mathrm{Ba}_{4}$ tetrahedra by hydride anions leading to a partial oxidation of polyanions and shortening of $T t$-Tt bonds.
\end{abstract}

\section{Introduction}

Zintl phases gained some interest as reversible hydrogen storage materials since they react under mild conditions, e.g. $\mathrm{CaSiH}_{1.3}[1,2], \mathrm{KSiH}_{3}[3,4]$ or $\mathrm{SrAl}_{2} \mathrm{H}_{2}[5,6]$. Chemisorbed hydrogen storage materials can be divided into (i)

$\begin{array}{llll}\text { Author } & \text { Title } & \text { File Name } & \text { Date } \\ \text { Henry Auer1, Sebastian } & \text { Reversible hydrogenation of the Zintl phases BaGe and BaSn studied } & \text { zintl_B2_Z- } & \text { Page } \\ \text { Weber1, Thomas Christian } & \text { by in situ diffraction } & \text { 19.12.2017 } & 1 \text { (20) } \\ \text { Hansen2, Daniel Maria } & & \\ \text { Többens3, Holger } & & \\ \text { Kohlmann1* } & & \end{array}$


ionic (e.g. $\mathrm{MgH}_{2}$ ) or (ii) complex metal hydrides (e.g. $\mathrm{NaAlH}_{4}$, or $\mathrm{LiBH}_{4}$ ) or (iii) molecular hydrides (e.g. $\mathrm{NH}_{3} \mathrm{BH}_{3}$ ). [7-12]. Ionic metal hydrides like $\mathrm{MgH}_{2}$ exhibit strong Coulomb interactions of the hydride anions with metal cations and thus show high desorption temperatures. In complex metal hydrides like alanates or boronates, however, hydrogen is covalently bound to an element forming a complex anion. Unfortunately, these systems show poor rehydrogenation properties and often need catalysts to react in a reasonable temperature-pressure regime.

Zintl phase hydrides can either incorporate hydrogen on interstitial sites or covalently bound to the polyanion (review: [13]), thus showing features of ionic as well as complex hydrides. Furthermore, both bonding schemes can appear next to each other and might help to overcome the problems mentioned above. Additionally, they allow the use of light and inexpensive elements like calcium, potassium, aluminium, silicon, etc. Since Zintl phase hydrides features both, saltlike and complex hydride moieties, decomposition occurs usually at moderate temperatures, e.g. $414 \mathrm{~K}$ for $\mathrm{KSiH}_{3}$ [3] and $523 \mathrm{~K}$ for $\mathrm{CaSiH}_{1.3}$ [1] at $0.1 \mathrm{MPa}$, and show good reversibility.

In situ diffraction has proven to be a valuable tool to study such solid-state gas reactions (recent reviews: [14] for neutron, [15] for X-ray diffraction.) To investigate the incorporation of hydrogen into crystalline structures the use of neutron radiation is often mandatory to localize hydrogen (or more often deuterium) positions. There are several examples demonstrating the benefit of such studies. In situ diffraction of the reaction of $\mathrm{Li}_{3} \mathrm{~N}+\mathrm{H}_{2}=\mathrm{LiNH}_{2}+2 \mathrm{LiH}$, which is an example of a hydrogen storage system due to its reversibility, showed quite different reaction paths depending on the temperature-pressure conditions.[16, 17] Previous studies on the reaction of Zintl phases with hydrogen revealed that reactions happen in one step forming line phases $[18,19]$ or show intermediate phases with large homogeneity ranges regarding hydrogen [20].

The AeTt $-\mathrm{H}_{2}(A e=\mathrm{Ca}-\mathrm{Ba}, T t=\mathrm{Si}-\mathrm{Sn})$ systems show hydrogen rich phases incorporating ionic hydride anions as well as hydrogen covalently bound to the $T t$ polyanions. [2, $21,22]$ For the $\mathrm{SrGe}-\mathrm{H}_{2}$ system it was shown that the breaking of covalent $\mathrm{Ge}-\mathrm{H}$ bonds is accompanied by a release of ionic hydrogen from interstitial sites. [20, 23]

This contribution extends the mechanistic understanding of hydrogen uptake and release of Zintl phases using in situ thermal analysis and diffraction. We use the heavy element representatives of the AeTt system, i.e. BaGe and $\mathrm{BaSn}$, since they show better reactivity than the silicides. Three new, hydrogen poor compounds $(\mathrm{y}<1)$ are described that are intermediates in the formation and decomposition of the hydrogen rich phases $\mathrm{BaTt}_{\mathrm{y}}, 1<\mathrm{y}<2$. 


\section{Experimental}

\section{Synthesis}

All preparations were done in an argon filled glove box ( $<1$ ppm $\mathrm{H}_{2} \mathrm{O}, \mathrm{O}_{2}$ ).

The Zintl phases $\mathrm{BaGe}$ and $\mathrm{BaSn}$ were prepared from the elements (Ba: rod, $99.3 \%$ (ca. 0.7\% Sr); Ge: ChemPur, 99.9999\%; Sn: powder, ChemPur, 99+\%). Stoichiometric mixtures of barium and germanium or barium and tin were sealed inside a niobium ( $\mathrm{BaGe})$ or stainless steel $(\mathrm{BaSn})$ metal jacket, which was heated under primary vacuum (0.1 Pa, active pumping). BaGe was melted at $1373 \mathrm{~K}$ and subsequently annealed at $1173 \mathrm{~K}$ for $40 \mathrm{~h}$. BaSn was annealed at $1273 \mathrm{~K}$ for $48 \mathrm{~h}$, then ground and annealed at $1273 \mathrm{~K}$ for $48 \mathrm{~h}$ again.

\section{Thermal analysis}

Differential scanning calorimetry was done in situ under hydrogen pressure $\left(\mathrm{H}_{2}\right.$-DSC). Measurements were performed with a Q1000 DSC (TA Instruments) equipped with a gas pressure chamber. Aluminum crucibles were filled with about 15-20 mg of the Zintl phase and crimped within a glovebox. Thus, the container was tight against air but still allows hydrogen to penetrate. Samples were placed in the pressure chamber, which was then flushed with hydrogen (Air Liquide, 99.9\%) for three times before it was set to the desired starting pressure. Due to isocore set up, the pressure increased during a measurement as shown in the corresponding figures. Samples were heated at a rate of $10 \mathrm{~K} \mathrm{~min}^{-1}$ to a maximum temperature of $700 \mathrm{~K}$. The temperature was usually held for $10 \mathrm{~min}$. In subsequent runs, lower maximum temperatures were used depending on the occurring signals. The heating was then stopped right after a reaction step, and the temperature was held there for $10 \mathrm{~min}$ before cooling to room temperature and ex situ XRPD characterisation.

\section{Laboratory X-ray powder diffraction (XRPD)}

Ex situ XRPD was done using monochromatic $\mathrm{Cu}-\mathrm{K}_{\alpha 1}-$ radiation either on a Huber G670 Guinier diffractometer with image plate detector or on a Stoe Stadi P DebyeScherrer diffractometer with Mythen $1 \mathrm{~K}$ detector.

\section{In situ synchrotron powder diffraction (in situ SPD)}

SPD was done at KMC-2 beamline [24] of BESSY II at Helmholtz-Zentrum Berlin (HZB), Germany, using radiation with $\lambda=118.08(2) \mathrm{pm}(10.5 \mathrm{keV})$. For in situ measurements $0.3 \mathrm{~mm}$ fused silica capillaries were used, glued into $1 / 4$ in VCR-fittings using two component epoxy glue, and attached to a gas handling system $\left(\mathrm{H}_{2}\right.$ : $\left.99.999 \%\right)$. Heating was realised using a hot air jet. As sample rotation was 
not yet possible, the resulting poor crystallite statistics allowed qualitative evaluation of the reaction only.

\section{In situ neutron powder diffraction (in situ NPD)}

In situ NPD was done at the high intensity D20 instrument [25] at the Institut Laue Langevin (ILL), Grenoble, France. Measurements were done at $\lambda=186.819$ (3) pm, which was calibrated by an external silicon NIST640b standard sample in a $5 \mathrm{~mm}$ vanadium container. In situ experiments were done in (leuco-)sapphire single-crystal cells with $6 \mathrm{~mm}$ inner diameter, which were connected to a gas supply system (for more details, see $[23,26]$ ). Due to the singlecrystalline character of the cell a proper orientation leads to almost no background contribution of the container. For the in situ investigations, the sapphire cell was filled with the Zintl phase within a glove box. After attaching to the gas supply system on the diffractometer the reaction chamber was pressurized with $\mathrm{D}_{2}$ (Air Liquide, $99.8 \%$ isotope purity) at ambient temperature. Heating was realized using two laser beams.

All data sets obtained on the ILL D20 instrument are presented with an additional label according to internal raw data labelling (NUMOR labelling). Data refer to proposal 5-22-734 [27].

\section{Rietveld refinement and crystal structure pic- tures}

Crystal structures were Rietveld refined [28, 29] using FULLPROF [30,31] (BaSn-D 2 experimentes) or TOPAS [32] (BaGe- $\mathrm{D}_{2}$ experiments). In situ data set were evaluated in sequential refinements. Structure pictures were prepared by VESTA [33, 34]. Structural data were normalized using STRUCTURE TIDY [35] as implemented in VESTA.

\section{Results and Discussion}

\section{Preliminary Considerations}

The AeTt Zintl-phase family $(A e=$ alkaline earth metal, $T t=$ tetrel / group 14 element) shows a rich hydogenation chemistry. For the $\mathrm{SrGe}-\mathrm{H}_{2}$ system three hydride phases are known already. There are hydrogen rich $\gamma-\mathrm{SrGeH}_{\mathrm{y}}, 1.10<$ $\mathrm{y}<1.23,[20,21,23]$ as well as two hydrogen poor phases $\alpha-\mathrm{SrGeH}_{\mathrm{y}}, \mathrm{y}<0.3$ and $\beta-\mathrm{SrGeH}_{\mathrm{y}}$, that shows a homogeneity range of at least $0.47<\mathrm{y}<0.75 .[20,23]$

The Zintl phases $A e T t, A e=\mathrm{Ca}-\mathrm{Ba} T t=\mathrm{Si}-\mathrm{Pb}$, crystallize in CrB-structure type (space group type $\mathrm{Cmcm}$, No. 63). According to the Zintl-Klemm concept we suspect two-binding $\mathrm{Si}^{2-}$-ions, which form ${ }^{1}{ }_{\infty}\left[\mathrm{Si}^{2-}\right]$-zigzag chains. Alkaline earth metal atoms form sheets of connected $A e_{4}$ tetrahedra that are compressed along the crystallographic $b$ direction. 


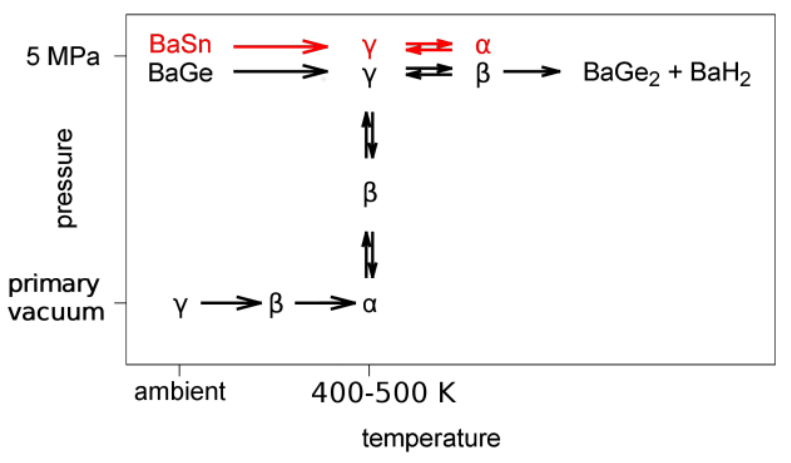

Fig. 1. Reaction scheme for the hydrogenation of BaGe (black) and $\mathrm{BaSn}$ (red) showing irreversible and reversible formation steps. Approximate compositions are $\alpha-\mathrm{BaTt}_{\mathrm{H}}(0<\mathrm{y}<0.36), \beta-$ $\mathrm{BaGeH}_{\mathrm{y}}(\mathrm{y}=0.5)$ and $\gamma-\mathrm{BaTtH}_{\mathrm{y}}(1<\mathrm{y}<1.67),(T t=\mathrm{Ge}$ or $\mathrm{Sn}$, no $\beta-\mathrm{BaSnH}_{\mathrm{y}}$ obtained).

Upon formation of $\alpha$ - and $\beta$-phases with less than one equivalent hydrogen per formula unit, tetrahedral $A e_{4}-$ voids are occupied and the $T t^{2-}$ polyanions are partially oxidized. As DFT calculations of the hydrogen free phases have shown, there are already partially filled (oxidized) $\pi^{*}$ bands at the Fermi edge [36, 37, 38], due to Tt-p-Ae-d interaction. Upon incorporation of hydrogen these bands are further oxidized increasing bond strength within the zigzag chain and shortening the bond lengths [20, 21, 22]. A similar effect was described for the solid solutions $\mathrm{CaGa}_{\mathrm{x}} T t_{1-\mathrm{x}}$ $(T t=\mathrm{Si}(\mathrm{x} \leq 0.6), \mathrm{Sn}(\mathrm{x} \leq 0.4))$ [39] where electron poor Zintl phases are formed since gallium ions formally have only 5 valence electrons instead of 6 . Replacing the alkaline earth metal by an alkaline metal in AeTt has a similar effect as partial oxidation by hydrogen. Thus, a bond length shortening within the chain was found in $\mathrm{Na}_{0.14} \mathrm{Sr}_{0.86} \mathrm{Ge}$. [40]

Thermal analysis (see below) of the reaction of $\mathrm{BaGe}$ and $\mathrm{BaSn}$ with gaseous hydrogen suggests the occurrence of similar hydrogen poor phases as obtained for the $\mathrm{SrGe}-\mathrm{H}_{2}$ system, i.e. $\alpha-\mathrm{BaGeH}_{\mathrm{y}}$ and $\alpha-\mathrm{BaSnH}_{\mathrm{y}}(\mathrm{y}<0.4)$ and $\beta-\mathrm{BaGeH}_{\mathrm{y}}(\mathrm{y}=0.5)$. Therefore, the recently described phases $\mathrm{BaGeH}_{5 / 3-\mathrm{x}}$ [22] and $\mathrm{BaSnH}_{4 / 3-\mathrm{x}}$ [21] will be called $\gamma$ $\mathrm{BaGeH}_{\mathrm{y}}$ and $\gamma-\mathrm{BaSnH}_{\mathrm{y}}$, respectively. $\alpha$ - and $\beta$-phases are typical decomposition products at high temperatures. $\gamma$ phases release hydrogen under vacuum conditions as well as under hydrogen pressure forming the hydrogen poor phases. Fig. 1 gives a schematic overview of the conditions were the different phases are obtained. Before the reactions are discussed as determined by in situ thermal analysis and diffraction, the structures of the new compounds will be discussed in detail. 


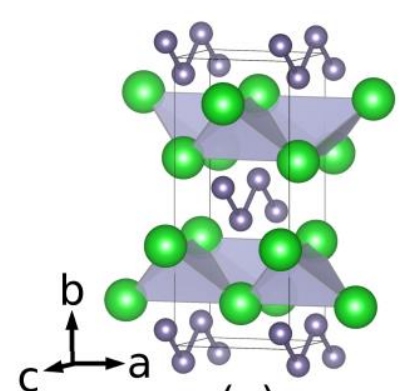

(a)

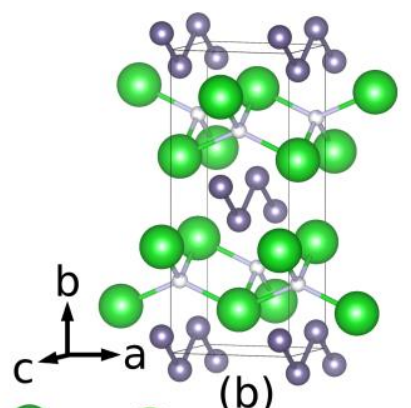

(b)

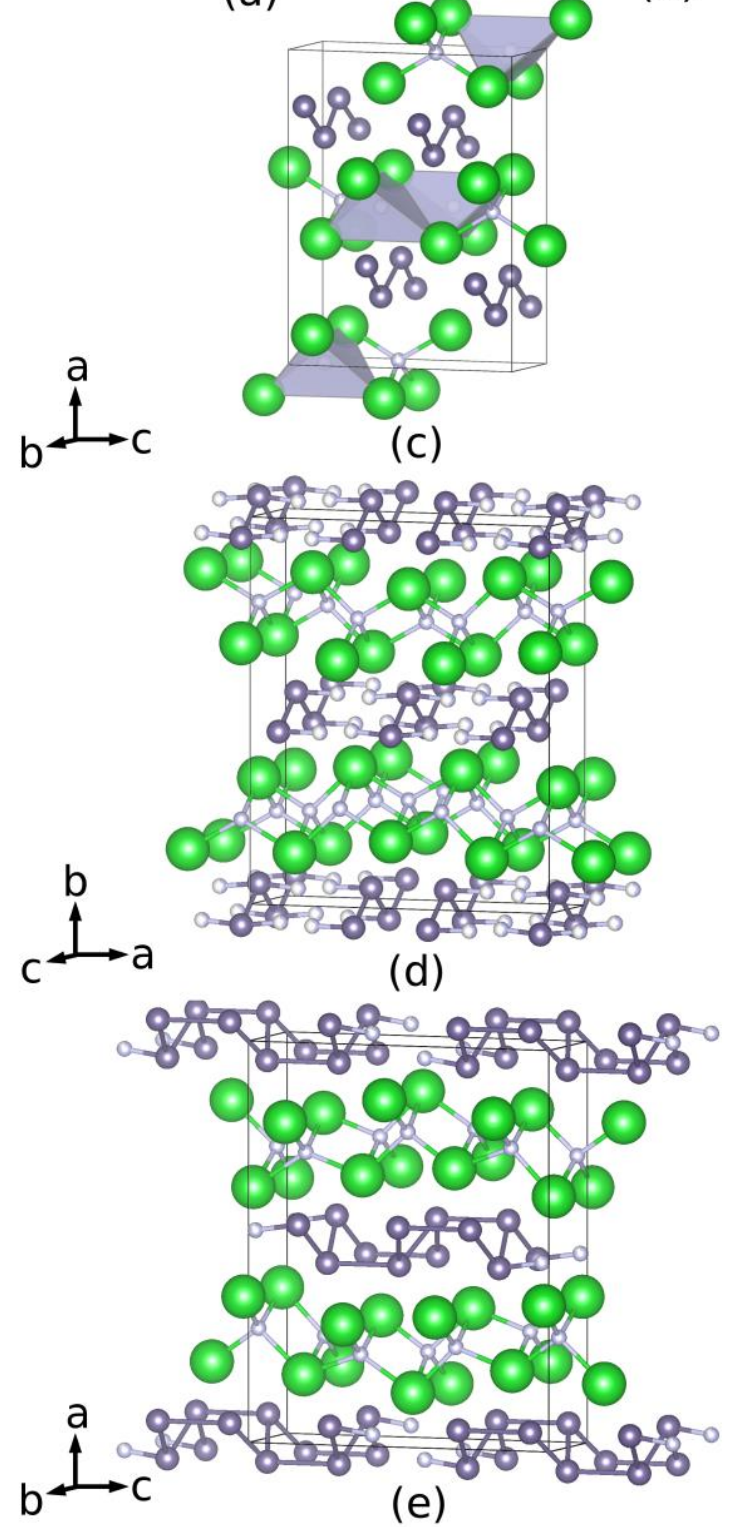

Fig. 2. Crystal structures of (a) BaGe / BaSn ( $\mathrm{Cmcm})$, (b) $\alpha$ $\mathrm{BaGeD}_{\mathrm{y}} / \alpha-\mathrm{BaSnD}_{\mathrm{y}}(\mathrm{Cmcm})$, (c) $\beta-\mathrm{BaGeD}_{\mathrm{y}}\left(\right.$ Pnma $, a^{\prime}=b, b^{\prime}=c$, $\left.c^{\prime}=2 a ;(1 / 4,1 / 4,0)\right)$, (d) $\gamma$-BaGeD (averaged Cmcm-model, the germanium binding D sites are about half occupied (see [22], $a^{\prime}=$ $3 a)$ and (e) $\gamma$-BaSnDy $\left(\right.$ Pnma $\left., a^{\prime}=b, b^{\prime}=c, c^{\prime}=3 a\right)$. Grey tetrahedra show voids of the hydrogen free Zintl phase and the almost empty deuterium site (D2, SOF $=0.05(3)$, see Tab 4) of $\beta$ $\mathrm{BaGeD}_{\mathrm{y}}$. Space groups are given in regard to the parent Zintl phase. Large, green spheres: Ba; medium, grey spheres: Ge / Sn; small white spheres: H/D. 


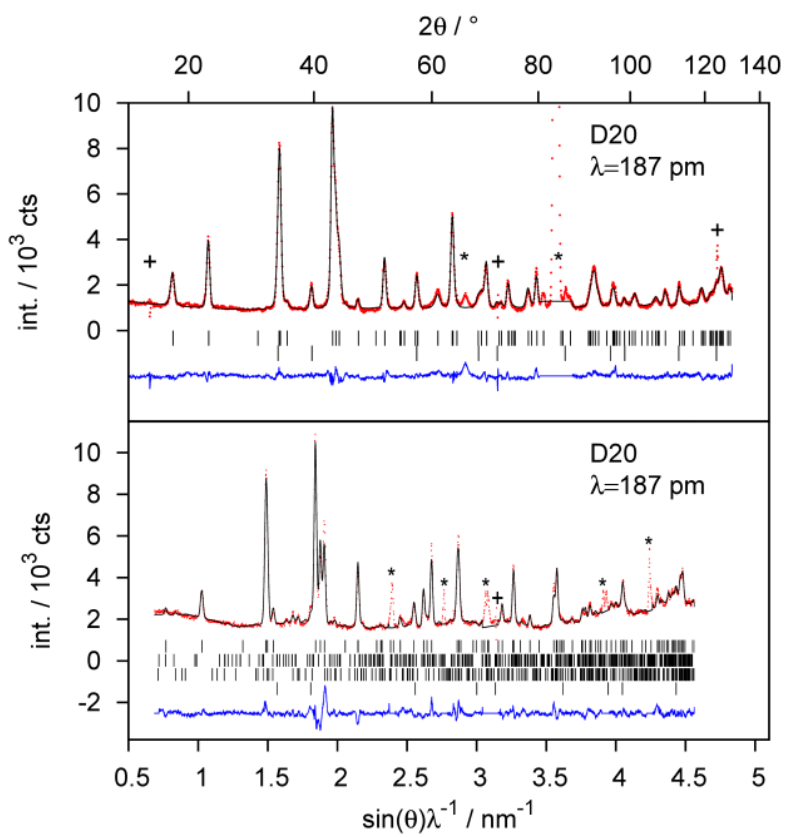

Fig. 3. Rietveld refinement of the crystal structures of (top) $\alpha$ $\mathrm{BaGeD}_{0.131(5)}(C m c m, a=503.09(3) \mathrm{pm}, b=1221.5(2) \mathrm{pm}, c=$ 427.38(4) pm; 325(6) K, primary vacuum; Bragg-marker from top: $\left.\alpha-\mathrm{BaGeD}_{0.13}, \mathrm{BaO}(6 \mathrm{wt}-\%) ; R_{\mathrm{wp}}=6.9 \%, R_{\mathrm{p}}=4.9 \%, S=2.7\right)$ and (bottom) $\alpha-\mathrm{BaSnD}_{0.188(4)}(\mathrm{Cmcm}, a=522.72(6) \mathrm{pm}, b=$ 1293.6(2) pm, $c=463.97(6) \mathrm{pm} ; 478(5) \mathrm{K}, 5.2(1) \mathrm{MPa} \mathrm{D}_{2}$ pressure; Bragg-marker from top: $\alpha-\mathrm{BaSnD}_{0.19}, \gamma$-BaSnD $\mathrm{Bn}_{1.3}(2 \mathrm{wt}-$ $\%), \mathrm{Ba}_{3} \mathrm{Sn}_{5}$ (4 wt- $\left.\%\right), \mathrm{BaO}(1 \mathrm{wt}-\%) ; R_{\mathrm{wp}}=5.5 \%, R_{\mathrm{p}}=4.2 \%, S$ $=2.7$ ). Diffraction data are taken from the in situ experiment, thus some reflections of the sapphire cell (*) are present. Defect detector cells are marked with (+).

\section{Crystal structures of $\alpha-B a D_{y}, \alpha-B_{a S n D}$ and $\beta$-BaGeD,$y<1.0$}

Using in situ neutron diffraction data the crystal structures (see Fig. 2) of the deuterides $\alpha-\mathrm{BaGeD}_{\mathrm{y}}, \alpha-\mathrm{BaSnD}_{\mathrm{y}}$ and $\beta-\mathrm{BaGeD}_{\mathrm{y}}, \mathrm{y}<1.0$ were determined and refined [41].

The crystal structures of the $\alpha$-phases of the BaTt$\mathrm{H}_{2}$ system $(T t=\mathrm{Ge}, \mathrm{Sn})$ were Rietveld refined using a model isotypic to $\alpha-\mathrm{SrGeH}_{\mathrm{y}}$ (Fig. 3 and S3; Tab 1, 2 and S3). Due to technical issues (see description of the in situ experiment below) the refinement of $\alpha-\mathrm{BaSnD}_{\mathrm{y}}$ shows some misfits. The crystal structure of the parent Zintl phases is preserved, but especially lattice parameter $b$ is elongated when tetrahedral $\mathrm{Ba}_{4}$-voids are partially filled with hydrogen.

They appear as decomposition products of the more hydrogen rich $\beta$ - and $\gamma-\mathrm{BaGeH}_{\mathrm{y}}$ or $\gamma-\mathrm{BaSnH}_{\mathrm{y}}$ under reduced pressure or at high temperatures (Fig. 1). Depending on preparation conditions, the deuterium content is variable indicating a homogeneity range. $\alpha-\mathrm{BaGeD}_{0.131(5)}$ was formed from $\gamma-\mathrm{BaGeD}_{\mathrm{y}}$ under vacuum (ca. $10 \mathrm{~Pa}$ ) and a maximum temperature of 450(2) K. It was recovered at room temperature. Heating $\beta-\mathrm{BaGeD}_{\mathrm{y}}$ for at least $30 \mathrm{~min}$ at the same pressure and 502(2) $\mathrm{K}$ leads to $\alpha-\mathrm{BaGeD}_{0.095(7)}$. $\gamma-\mathrm{BaSnD}_{\mathrm{y}}$ decomposes at ca. $430 \mathrm{~K}$ and 5.0(1) $\mathrm{MPa} \mathrm{D}_{2}$ (in situ diffraction, see below) into $\alpha-\mathrm{BaSnD}_{0.188(4)}$ or at ca.

Author

Henry Auer1, Sebastian

Weber1, Thomas Christian

Title

Hansen2, Daniel Maria

Többens3, Holger

Kohlmann1*
File Name

zintl_B2_Z Krist.docx
Date

19.12.2017
Page 7 (20)
Reversible hydrogenation of the Zintl phases BaGe and BaSn studied by in situ diffraction
. 
$450 \mathrm{~K}$ and 5.5(1) $\mathrm{MPa} \mathrm{H}_{2}\left(\mathrm{H}_{2}-\mathrm{DSC}\right.$, see below). This phase was not recovered at room temperature since a reversible formation of $\gamma-\mathrm{BaSnD}_{\mathrm{y}}$ occured upon cooling under $5 \mathrm{MPa}$ $\mathrm{D}_{2}$ at ca. $425 \mathrm{~K}$.

Within the whole AeTt $-\mathrm{H}_{2}$ system, lattice parameter $c$ regarding the CrB-type Zintl phases (direction of the zigzag chains) is hardly affected by the hydrogenation. The other lattice parameters strongly change. Therefore, the $b / c$ ratio is a good measure for a structural change. Hydrogen free BaGe shows $b / c=2.78-2.79$ depending on the temperature. This value increases to 2.83 and finally to 2.86 with increasing hydrogen content of the $\alpha$-phase (Tab. 3). The $b / c$-ratio increases from 2.69 in hydrogen free BaSn to 2.79 in $\alpha-\mathrm{BaSnD}_{0.188(4)}$. Thus, it is a proper measure for the hydrogen incorporation in low concentrations.

Table 1. Structural data of the $\alpha$-phase $\mathrm{BaGeD}_{0.131(5)}, 325(6) \mathrm{K}$, sapphire cell, primary vacuum (10 Pa), Cmcm, $a=503.09(3) \mathrm{pm}$, $b=1221.5(2) \mathrm{pm}, c=427.38(4) \mathrm{pm}, \mathrm{d}(\mathrm{Ge}-\mathrm{Ge})=261.6(6) \mathrm{pm}$, $\Varangle(\mathrm{Ge}-\mathrm{Ge}-\mathrm{Ge})=109.5(3)^{\circ}$. Structural data of $\alpha-\mathrm{BaGeD}_{0.095(7)}$ are given in Tab. S3.

\begin{tabular}{llllll} 
atom & $x$ & $y$ & $z$ & $\begin{array}{l}B_{\text {iso }} / \\
10^{4} \mathrm{pm}^{2}\end{array}$ & $\mathrm{SOF}$ \\
\hline $\mathrm{Ba}$ & 0 & $0.3578(3)$ & $1 / 4$ & $0.62(13)$ & \\
$\mathrm{Ge}$ & 0 & $0.0618(4)$ & $1 / 4$ & $1.80(10)$ & \\
$\mathrm{D}$ & 0 & $0.767(3)$ & $1 / 4$ & $0.7(8)$ & $0.131(5)$
\end{tabular}

Table 2. Structural data of the $\alpha$-phase $\mathrm{BaSnD}_{0.188(4)}, 478(5) \mathrm{K}$, sapphire cell, 5.2(1) $\mathrm{MPa} \mathrm{D}_{2}$ pressure, Cmcm, $a=522.72(6) \mathrm{pm}$, $b=1293.60(15) \mathrm{pm}, c=463.97(6) \mathrm{pm}, \mathrm{d}(\mathrm{Sn}-\mathrm{Sn})=294.0(3) \mathrm{pm}$, $\Varangle(\mathrm{Sn}-\mathrm{Sn}-\mathrm{Sn})=104.2(3)^{\circ}$.

\begin{tabular}{llllll} 
atom & $x$ & $y$ & $z$ & $\begin{array}{l}B_{\text {iso }} / \\
10^{4} \mathrm{pm}^{2}\end{array}$ & SOF \\
\hline $\mathrm{Ba}$ & 0 & $0.3530(3)$ & $1 / 4$ & $3.58(6)^{\mathrm{a}}$ & \\
$\mathrm{Sn}$ & 0 & $0.0698(3)$ & $1 / 4$ & $3.58^{\mathrm{a}}$ & \\
$\mathrm{D}$ & 0 & $0.7531(12)$ & $1 / 4$ & $4.58^{\mathrm{a}}$ & $0.188(4)$
\end{tabular}

${ }^{a}$ Due to similar molar mass (Ba and $\mathrm{Sn}$ ) and some problems with adjustment of the single crystal cell, constraints were set to $B_{\text {iso }}(\mathrm{Ba})=B_{\text {iso }}(\mathrm{Sn})=B_{\text {iso }}(\mathrm{D})$-offset; offset $=1.0$. Varying the offset did not change the $\mathrm{SOF}(\mathrm{D})$ significantly (offset $=0.0$ to $2.0: 2$ e.s.u. variation, offset $=3.0$ : 3 e.s.u.)

Table 3. Lattice parameters of the parent Zintl phases, $\alpha$ - and $\beta$ $\mathrm{BaTt}_{\mathrm{y}}(T t=\mathrm{Ge}, \mathrm{Sn})$ determined by neutron powder diffraction.

\begin{tabular}{llllllll} 
Phase $^{\mathrm{a}}$ & $\mathrm{y}$ & $T / \mathrm{K}$ & $a / \mathrm{pm}$ & $b / \mathrm{pm}$ & $c / \mathrm{pm}$ & $b / c$ & $\mathrm{~d}(T t-T t) / \mathrm{pm}$ \\
\hline $\mathrm{BaGe}$ & & $298(2)$ & $506.58(2)$ & $1195.5(2)$ & $430.27(2)$ & 2.78 & $267.6(4)$ \\
$\mathrm{BaGe}$ & $502(2)$ & $507.50(4)$ & $1206.0(2)$ & $431.65(4)$ & 2.79 & $269.5(4)$ \\
$\alpha-\mathrm{BaGeD}_{\mathrm{y}}$ & $0.095(7)$ & $502(2)$ & $505.66(4)$ & $1218.0(2)$ & $429.85(4)$ & 2.83 & $266.5(6)$ \\
$\alpha-\mathrm{BaGeD}_{\mathrm{y}}{ }^{\mathrm{b}}$ & $0.131(5)$ & $325(6)$ & $503.09(3)$ & $1221.5(2)$ & $427.38(4)$ & 2.86 & $261.6(6)$ \\
$\beta-\mathrm{BaGeD}_{\mathrm{y}}{ }^{\mathrm{c}}$ & $0.488(11)$ & $502(2)$ & $1 / 2 c^{\prime}=$ & $a^{\prime}=$ & $b^{\prime}=$ & $a^{\prime} / b^{\prime}=$ & $257.1(7)$ \\
& & & $495.77(4)$ & $1319.5(2)$ & $421.46(2)$ & 3.13 & \\
$\mathrm{BaSn}$ & & $298(2)$ & $532.79(5)$ & $1251.10(10)$ & $465.89(4)$ & 2.69 & $301.0(5)$ \\
$\alpha-\mathrm{BaSnD}_{\mathrm{y}}$ & $0.188(4)$ & $478(5)$ & $522.72(6)$ & $1293.6(2)$ & $463.97(6)$ & 2.79 & $294.0(3)$
\end{tabular}

${ }^{a}$ All phases crystallize in spacegroup $\mathrm{Cmcm}$, exept $\beta-\mathrm{BaGeH}_{\mathrm{y}}$ which cystallizes in space group type Pnma; ${ }^{\mathrm{b}}$ dehydrogenated at $T_{\max }=450(2) \mathrm{K} ;{ }^{\mathrm{c}}$ axes reordered and normalised with respect to the $\mathrm{CrB}$-structure type to gain comparability.

Author

Title

Henry Auer1, Sebastian

Weber1, Thomas Christian

Hansen2, Daniel Maria

Többens3, Holger

Kohlmann1*
Reversible hydrogenation of the Zintl phases BaGe and BaSn studied by in situ diffraction
File Name zintl_B2_Z Krist.docx 
The Ge-Ge distance of BaGe was evaluated as 267.6(4) pm $(298(2) \mathrm{K})$ and $269.5(4) \mathrm{pm}(502(2) \mathrm{K})$. The angle within the zigzag chain is $106.4(2)^{\circ}$ or $107.0(2)^{\circ}$ respectively. BaSn shows a Sn-Sn distance of 301.0(5) pm and a chain angle of $101.4(3)^{\circ}(298(2) \mathrm{K})$. Upon formation of the $\alpha$ phases, the chains are partially oxidized (e.g. $\mathrm{Ge}^{2-}+{ }^{y} / 2 \mathrm{H}_{2}$ $\left.\rightarrow \mathrm{Ge}^{(2-y)-}+y \mathrm{H}^{-}\right)$. Thus, a shortening of the bond lengths is observed. The change in $\mathrm{BaGe}$ is small with $\mathrm{d}(\mathrm{Ge}-\mathrm{Ge})=$ 261.6(6) pm for $\alpha-\mathrm{BaGeD}_{0.131(5)}$ at $325(6) \mathrm{K}$ and 266.5(6) pm for $\alpha-\mathrm{BaGeD}_{0.095(7)}$ at $502(2) \mathrm{K}$. The corresponding chain angles are $109.5(3)^{\circ}$ and $107.5(3)^{\circ}$, respectively. The formal germanium-electron count of $\alpha-\mathrm{BaGeD}_{0.131(5)}$ is comparable to $\mathrm{Na}_{0.14} \mathrm{Sr}_{0.86} \mathrm{Ge}$, which shows a similar bond length $\mathrm{d}(\mathrm{Ge}-\mathrm{Ge})=260.2(3) \mathrm{pm}$ ( $293 \mathrm{~K})$ [40]. The shortening of the $\mathrm{Sn}-\mathrm{Sn}$ bond length is similar and reaches d(Sn-Sn) $=294.0(3) \mathrm{pm}(478(5) \mathrm{K})$.

The chain angle increases to $104.2(3)^{\circ}$. The data are summarized in Tab. 3. Ba-D distances are slightly larger than in binary $\mathrm{BaH}_{2}$ (262 pm [42]) with 261(3)-279(3) pm in $\alpha-\mathrm{BaGeD}_{0.095(7)}$ and 269.5(9)-291.6(8) pm in $\alpha-\mathrm{BaSnD}_{0.188(4)}$.

While the $\alpha$-phases show a statistical occupation of tetrahedral voids, the $\beta$-phases show hydrogen ordering. For $\beta-\mathrm{SrGeH}_{\mathrm{y}}$ a $2 \times 2$-fold superstructure regarding the parent Zintl phase was found.[20] Due to data quality only a preliminary structure model was presented. $\beta-\mathrm{BaGeH}_{\mathrm{y}}$ shows a twofold superstructure along crystallographic $a$ direction regarding the parent Zintl phase. The structure was determined with the aid of group-subgroup relations [43]. To reach a doubling of lattice parameter $a$ staying in orthorhombic crystal system at least two transitions of type $k 2$ (klassengleiche transition of index two) are necessary. These symmetry reductions lead to seven space group type candidates. Four of them describe all superstructure reflections according profile fitting. Only one structure model led to an ordered deuterium site occupation. Thus, the structure is described in space group type Pnma $\left(a^{\prime}=b, b^{\prime}=c, c^{\prime}=\right.$ $2 a$ ). The symmetry reduction leads to two independent crystallographic sites within $\mathrm{Ba}_{4}$-tetrahedra as possible deuterium positions. Rietveld refinement (Fig. 4, Tab. 4) of the crystal structure of $\beta-\mathrm{BaGeD}_{\mathrm{y}}$ results in one site (D1, Tab. 4) with 92.5(13)\% occupation and one nearly empty site (D2, Tab. 4) with 5.0(10)\% occupation giving an approximate composition of $\beta-\mathrm{BaGeD}_{0.5}$.

The filled tetrahedra are more regular than the nearly empty ones with typical Ba-D distances of 254.1(9) pm to 266(2) pm. These values are comparable to the binary hydride $\mathrm{BaH}_{2}$ with $262 \mathrm{pm}$ on average [42] and they are $5-10 \%$ smaller than in the $\alpha$-phases. The irregular, hardly filled tetrahedral voids show one strongly elongated Ba-D distance longer than $300 \mathrm{pm}$ and a strongly opened Ba-Ba edge.

While the effect on the interchain distances of the $\alpha$-phases is small, the shortening of the $\mathrm{Ge}-\mathrm{Ge}$ distance in $\beta-\mathrm{BaGeH}_{0.5}$ from 267.6(4) pm in $\mathrm{BaGe}$ to 257.1(7) pm in the hydride is much stronger. The bond length compares well to $\mathrm{Li}_{4} \mathrm{Ge}_{2} \mathrm{H}$, which shows $\mathrm{Ge}-\mathrm{Ge}$ zigzag chains as well with a Ge-Ge distance of 253 pm [44, 45]. Both examples can be described as Zintl phases with formally $\mathrm{Ge}^{1.5-}$ polyanions, which are oxidized in regard to the assumed

Author

Henry Auer1, Sebastian

Weber1, Thomas Christian

Hansen2, Daniel Maria

Többens3, Holger

Kohlmann1*
Title

Reversible hydrogenation of the Zintl phases BaGe and BaSn studied

by in situ diffraction
File Name

zintl_B2_Z Krist.docx
Date

19.12.2017
Page

9 (20) 
$\mathrm{Ge}^{2-}$ of a zigzag chain according to the Zintl concept. Thus, the shortened bond lengths correspond to an increased $\pi$ bonding due to a depopulation of $\pi^{*}$-bands upon hydrogenation.

\section{Thermal analysis}

In situ thermal analysis under hydrogen pressure ( $\mathrm{H}_{2}$-DSC) was conducted under several pressure conditions to investigate the reactions of $\mathrm{BaGe}$ and $\mathrm{BaSn}$ with hydrogen. The hydrogenation of $\mathrm{BaGe}$ shows the first strong exothermic signal above $373 \mathrm{~K}$ (Fig. 5). Between 3 to $5 \mathrm{MPa}$ starting pressure the signal does not significantly shift, but since it is broad the onset is not well defined. According to in situ diffraction (see below) and ex situ characterisation, this effect corresponds to the formation of $\gamma-\mathrm{BaGeH}_{\mathrm{y}}$. The partially formation of the $\beta$-phase already takes place at room temperature (see below, in situ NPD) but does not give any DSC signal. Since the reaction is quite slow and a heating range of $10 \mathrm{~K} \mathrm{~min}^{-1}$ was applied, the exothermic signal might mainly show the direct reaction of $\mathrm{BaGe}+\mathrm{y} / 2 \mathrm{H}_{2} \rightarrow$ $\gamma-\mathrm{BaGeH}_{\mathrm{y}}$. Subsequent cycles $\left(T_{\max }=475 \mathrm{~K}\right)$ did not result in further signals.

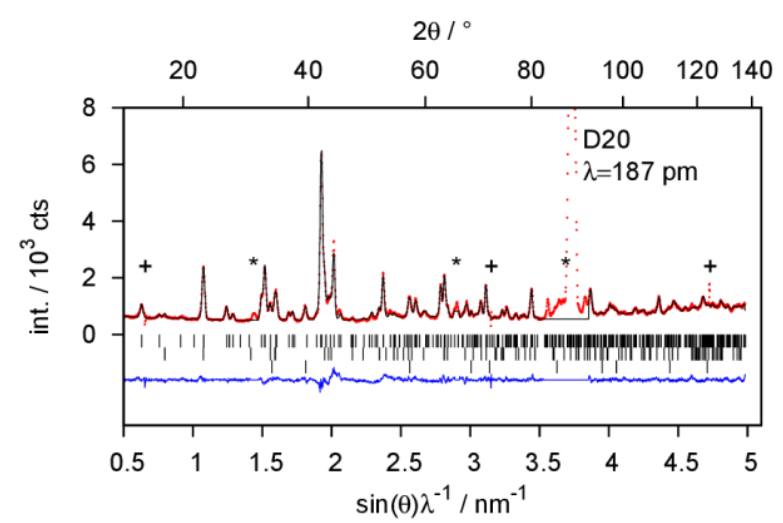

Fig. 4. Rietveld refinement of the crystal structure of $\beta$ $\mathrm{BaGeD}_{0.488(12)}$ (Pnma, $a=1319.5(2) \mathrm{pm}, b=421.46(2) \mathrm{pm}, c=$ 991.54(7) pm; 502(2) K, 0.20(5) MPa D ; Bragg-marker from top: $\beta-\mathrm{BaGeD}_{0.49}, \alpha-\mathrm{BaGeD}_{0.22}(25 \mathrm{wt}-\%), \mathrm{BaO}(6 \mathrm{wt}-\%) ; R_{\mathrm{wp}}=6.9 \%$, $\left.R_{\mathrm{p}}=4.9 \%, S=2.7\right)$ Diffraction data are taken from the in situ experiment, thus some reflections of the sapphire cell $(*)$ are present. Defect detector cells are marked with $(+)$.

Table 4. Structural data of the $\beta$-phase $\mathrm{BaGeD}_{0.488(12)}, 502(2) \mathrm{K}$, sapphire cell, 0.20(5) MPa D 2 pressure, Pnma, $a=1319.5(2) \mathrm{pm}$, $b=421.46(2) \mathrm{pm}, c=991.54(7) \mathrm{pm}, \mathrm{d}(\mathrm{Ge} 1-\mathrm{Ge} 2)=257.1(7)$ $\mathrm{pm}, \Varangle(\mathrm{Ge} 1-\mathrm{Ge} 2-\mathrm{Ge} 1)=110.1(5)^{\circ}$.

\begin{tabular}{llllll} 
atom & $x$ & $y$ & $z$ & $\begin{array}{l}B_{\text {iso }} / \\
10^{4} \mathrm{pm}^{2}\end{array}$ & SOF \\
\hline $\mathrm{Ba} 1$ & $0.1050(7)$ & $1 / 4$ & $0.1471(13)$ & $0.8(2)$ & \\
$\mathrm{Ba} 2$ & $0.1040(9)$ & $1 / 4$ & $0.6095(17)$ & $B_{\text {iso }}(\mathrm{Ba} 1)$ & \\
$\mathrm{Ge} 1$ & $0.3237(6)$ & $1 / 4$ & $0.3893(9)$ & $1.7(2)$ & \\
$\mathrm{Ge} 2$ & $0.2820(6)$ & $1 / 4$ & $0.8758(10)$ & $B_{\text {iso }}(\mathrm{Ge} 1)$ & \\
$\mathrm{D} 1$ & $0.0031(7)$ & $1 / 4$ & $0.3768(11)$ & $0.7(3)$ & $0.925(13)$ \\
$\mathrm{D}^{\mathrm{a}}$ & $\mathrm{x}(\mathrm{D} 1)+1 / 2$ & $3 / 4$ & $\mathrm{z}(\mathrm{D} 1)$ & $B_{\text {iso }}(\mathrm{D} 1)$ & $0.050(10)$
\end{tabular}

${ }^{a}$ symmetry condition as inherited from the original super group to fix this nearly empty site within the tetrahedral void.

Author

Henry Auer1, Sebastian

Weber1, Thomas Christian

Hansen2, Daniel Maria

Többens3, Holger

Kohlmann1*
Title

Reversible hydrogenation of the Zintl phases BaGe and BaSn studied by in situ diffraction
File Name zintl_B2_Z Krist.docx
Date 19.12.2017
Page 10 (20) 


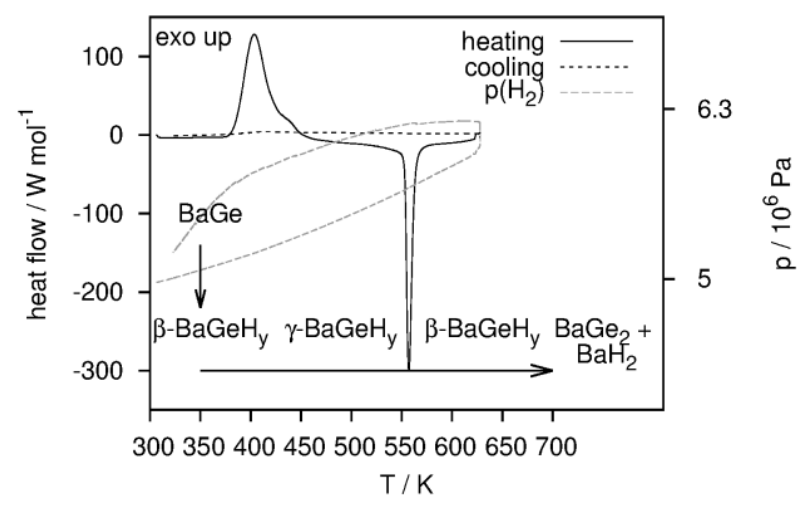

Fig. 5. In situ thermal analysis $\left(\mathrm{H}_{2}-\mathrm{DSC}\right)$ of the hydrogenation of BaGe.

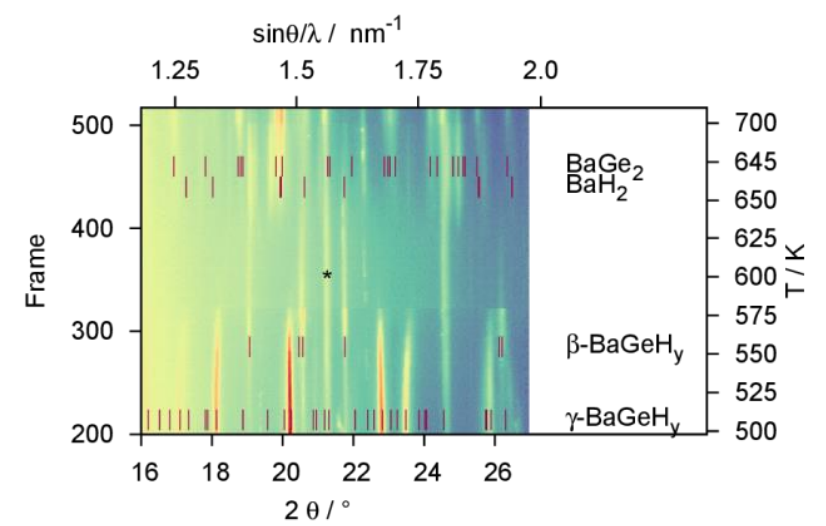

Fig. 6. 2D plot of in situ synchrotron powder diffraction (in situ SPD) of the hydrogenation of BaGe showing the high temperature region at $5 \mathrm{MPa} \mathrm{H}$ and $2 \mathrm{~K} \mathrm{~min}^{-1}$ heating rate $(20 \mathrm{~s} /$ frame data collection). (*) marks $\mathrm{BaO}$.

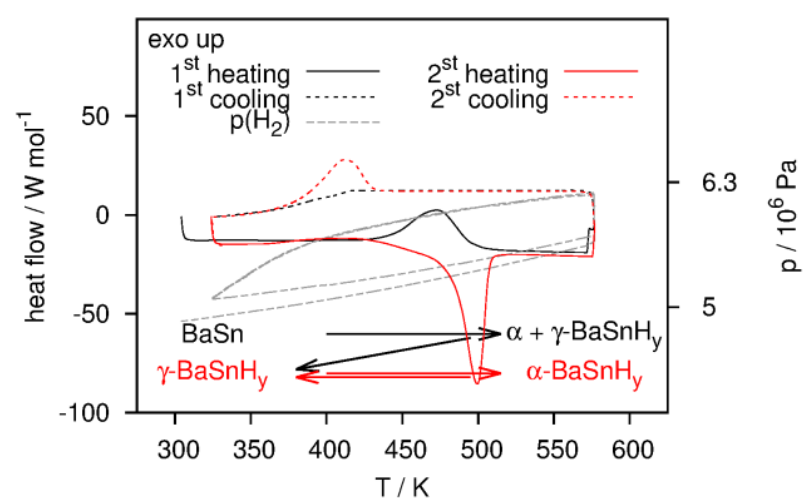

Fig. 7. In situ thermal analysis $\left(\mathrm{H}_{2}-\mathrm{DSC}\right)$ of the hydrogenation of $\mathrm{BaSn}$. A measurement starting directly from $\gamma-\mathrm{BaSnH}_{\mathrm{y}}$ reproduces run two (Fig. S5).

At $553 \mathrm{~K}$ and 5.7 $\mathrm{MPa} \mathrm{H}_{2}$ pressure an endothermic decomposition step occurs. With decreasing hydrogen pressure it shifts to $523 \mathrm{~K}$ at $3.4 \mathrm{MPa}$. From ex situ characterisation the decomposition product is not clear. Either $\gamma-\mathrm{BaGeH}_{\mathrm{y}}$ (although a reversible DSC signal could never be obtained) or a poorly crystalline product was present. Further heating at elevated pressures leads to the formation of $\mathrm{BaH}_{2}$ and $\mathrm{BaGe}_{2}$ as seen for the $\mathrm{SrGe}-\mathrm{H} 2$ system before [20]. In situ synchrotron diffraction showed that $\beta-\mathrm{BaGeH}_{\mathrm{y}}$

Author

Henry Auer1, Sebastian

Title

Weber1, Thomas Christian

Reversible hydrogenation of the Zintl phases BaGe and BaSn studied

Hansen2, Daniel Maria

Többens3, Holger

Kohlmann1*

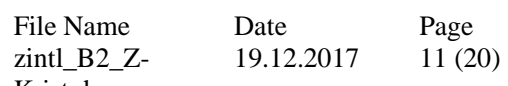

Zintl_B2_Z-

19.12.2017

11 (20) 
is formed and subsequently the decomposition in the germanium rich phase and binary hydride takes place (Fig 6). At pressures below $3 \mathrm{MPa} \mathrm{H}_{2} \gamma-\mathrm{BaGeH}_{\mathrm{y}}$ was not formed from $\mathrm{BaGe}$.

$\mathrm{H}_{2}$-DSC experiments of the hydrogenation of $\mathrm{BaSn}$ give different signals in the first cycle compared to the subsequent ones (Fig. 7). The first run at 5.0 MPa starting pressure shows an exothermic signal at $470 \mathrm{~K}$. Upon cooling no further signal is observed. Subsequent cycles show an endothermic signal at $500 \mathrm{~K}$ which was not observed during the first run. A corresponding exothermic signal at $410 \mathrm{~K}$ is obtained upon cooling. Ex situ characterised samples after one cycle show a mixture of $\alpha$ - and $\gamma-\mathrm{BaSnH}_{\mathrm{y}}$. After the second and subsequent cycles $\gamma-\mathrm{BaSnH}_{\mathrm{y}}$ is the main phase. Using $\gamma-\mathrm{BaSnH}_{\mathrm{y}}$ as starting material for the $\mathrm{H}_{2-}$ DSC experiment, the same patterns as for the second cycle is obtained (Fig. S5). According to in situ neutron diffraction (see below), the reversible decomposition step accounts for the formation of $\alpha-\mathrm{BaSnH}_{\mathrm{y}}$.

\section{In situ diffraction}

In situ diffraction experiments were done starting from the CrB-structure type Zintl phases BaGe and BaSn (Rietveld refinement: Fig S1, S2 and S4; Tab. S1, S2 and S4). The deuteration and dedeuteration of $\mathrm{BaGe}$ was studied under $5 \mathrm{MPa}$ deuterium pressure and primary vacuum respectively, using neutron diffraction, while the decomposition at high temperatures was studied by synchrotron diffraction at $5 \mathrm{MPa}$ hydrogen pressure. The reversible reaction between $\alpha$ - and $\beta-\mathrm{BaGeD}_{\mathrm{y}}$ was investigated isothermally at $502 \mathrm{~K}$. The reaction of $\mathrm{BaSn}$ was observed under $5 \mathrm{MPa}$ isobaric deuterium pressure.

\section{In situ diffraction of BaGe}

In situ neutron powder diffraction (NPD) of the reaction of $\mathrm{BaGe}$ under deuterium pressure and heating was done with 1 min time resolution. A first reaction step already happens at room temperature and low pressures of about 1-2 $\mathrm{MPa}$ (Fig. 8). As stated above, this is an effect that was not seen in the $\mathrm{H}_{2}$-DSC experiment. The obtained phase was indexed in the orthorhombic crystal system $(a=1309.1(13) \mathrm{pm}, b=$ 423.4(3) pm, $c=998.7(8) \mathrm{pm}, 298(2) \mathrm{K}$, 5.1(1) MPa, about $30 \%$ phase fraction) and therefore corresponds to $\beta$ -

$\mathrm{BaGeD}_{\mathrm{y}}$. The reflections are broad and Rietveld refinement of the structure was not possible. The phase fraction was estimated using the $\beta$ - $\mathrm{BaGeD}_{0.5}$-model described above. Thus, the deuteration reaction could not be evaluated using sequential Rietveld refinement.

After reaching $5 \mathrm{MPa}$ deuterium pressure, isobaric heating was started. The amount of $\beta-\mathrm{BaGeD}_{\mathrm{y}}$ did not increase, but at about $350 \mathrm{~K} \gamma-\mathrm{BaGeD}_{\mathrm{y}}$ starts to form, which corresponds to the exothermic DSC signal. In the beginning of this reaction the reflections are broad as well while they sharpen when higher temperatures are reached. The isothermic step at $425 \mathrm{~K}$ already shows a total formation of $\gamma-\mathrm{BaGeD}_{\mathrm{y}}$ (except for some $\mathrm{BaO}$ impurity). Isobaric heating was stopped at $505 \mathrm{~K}$. 


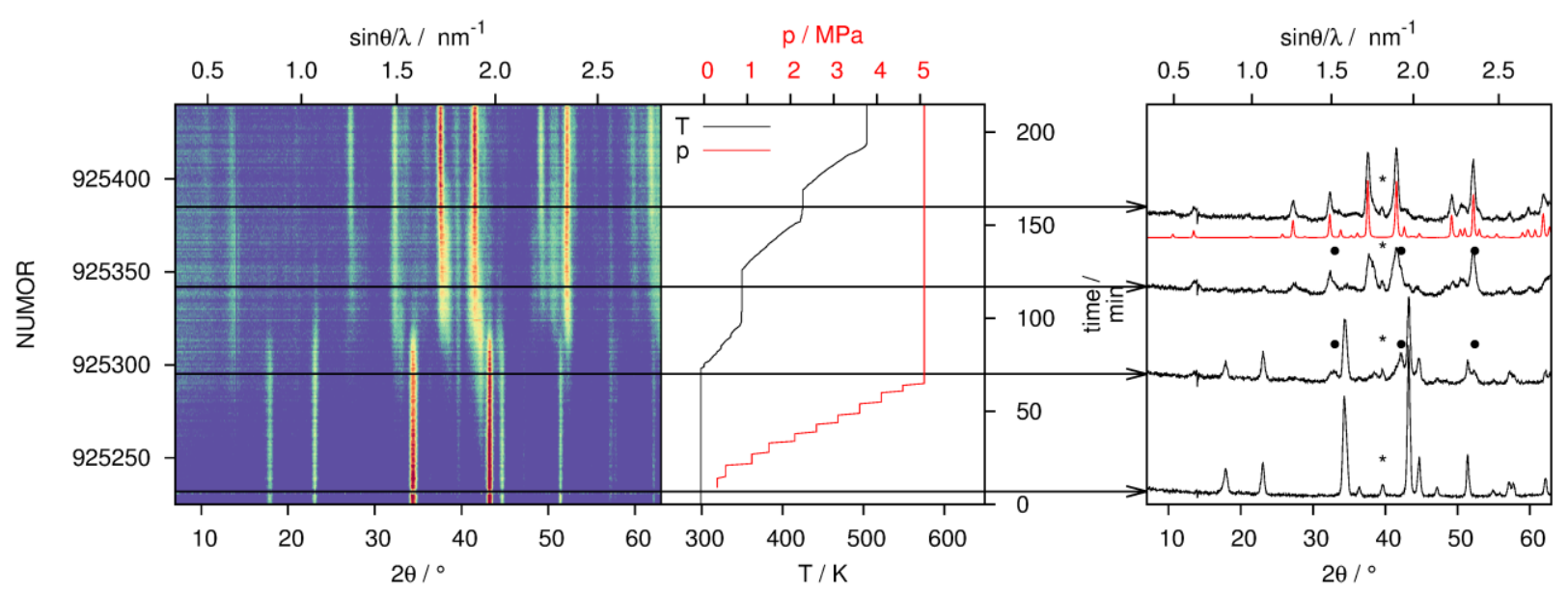

Fig. 8. 2D plot of in situ neutron powder diffraction starting with $\mathrm{BaGe}$ under $\mathrm{D}_{2}$ pressure (left) as well as selected diffraction patterns (right). The diffraction patterns show BaGe (bottom), the partially formation of $\beta-\mathrm{BaGeD}_{\mathrm{y}}$ (middle, marked as a bullet) and the formation of $\gamma-\mathrm{BaGeH}_{\mathrm{y}}$ (top, a simulation is given as red curve).(*) marks $\mathrm{BaO}$ (right). ILL raw data labelling (NUMOR) is given [27].

The decomposition at $5 \mathrm{MPa}$ hydrogen pressure and high temperatures was observed by in situ SPD (Fig. 6). At $580 \mathrm{~K}$ a hydrogen poor phase in the orthorhombic crystal system is formed. Metrical relations clearly indicate $\beta-\mathrm{BaGeH}_{\mathrm{y}}$. There is no sign towards the formation of the $\alpha$ phase. Upon further heating, the phase segregates into the germanium rich Zintl phase $\mathrm{BaGe}_{2}$ and $\mathrm{BaH}_{2}$ above $650 \mathrm{~K}$.

The in situ generated $\gamma-\mathrm{BaGeD}_{\mathrm{y}}$-phase was dedeuterated under primary vakuum $(10 \mathrm{~Pa})$, which was studied by in situ NPD (Fig. 9). Since crystallinity improved during the first heating cycle, sequential Rietveld refinement was possible. Phase fraction as well as hydrogen content was evaluated. At about $365 \mathrm{~K} \beta-\mathrm{BaGeD}_{\mathrm{y}}$ is formed again but is only stable in a small temperature window. Already at 400 $\mathrm{K} \alpha-\mathrm{BaGeD}_{\mathrm{y}}$ is formed. For the evaluation of $\gamma-\mathrm{BaGeD}_{\mathrm{y}} \mathrm{a}$ simplified model with three-fold superstructure $\left(a^{\prime}=3 a\right)$ with regard to the hydrogen free Zintl phase $\mathrm{BaGe}$ and spacegroup type $\mathrm{Cmcm}$ was used as described elsewhere (Fig. 2, for more details see Ref. [22] and its Supporting Information). Since there is no evidence for a deuterium release from tetrahedral voids, their occupation was kept fixed at $100 \%$. The occupation of the two about $50 \%$ filled chain binding deuterium sites (split position) were constraint to the same value and refined. Fig. 9 shows the sum of these sites which is constant up to $365 \mathrm{~K}$ and shows no sign for a homogeneity range. The averaged composition is $\gamma-\mathrm{BaGeD}_{\mathrm{y}}, \mathrm{y}=1.61(2)$, which is about the previously published value $\mathrm{y}=1.57(3)$ [22].

The temperature region from $365 \mathrm{~K}$ to $425 \mathrm{~K}$ is characterised by severe overlap of all three deuteride phases. Therefore, all parameters of $\gamma-\mathrm{BaGeD}_{\mathrm{y}}$ except for the scaling were kept fixed. Nonetheless, deuterium occupations of $\beta-\mathrm{BaGeD}_{\mathrm{y}}$ strongly correlate with the occurrence of $\alpha-\mathrm{BaGeD}_{\mathrm{y}}$ and the residual $\gamma-\mathrm{BaGeD}_{\mathrm{y}}$. The occupation of D1 (Tab. 4) goes down a bit, but shows full occupation after $\gamma-\mathrm{BaGeD}_{\mathrm{y}}$ was removed from the sequential refinement. The second tetrahedral void site (D2, Tab. 4) stays empty. Therefore, the varying occupation might be an arte-

$\begin{array}{lllll}\text { Author } & \text { Title } & \text { File Name } & \text { Date } & \text { Page } \\ \text { Henry Auer1, Sebastian } & \text { Reversible hydrogenation of the Zintl phases BaGe and BaSn studied } & \text { zintl_B2_Z- } & 19.12 .2017 & 13(20) \\ \text { Weber1, Thomas Christian } & \text { by in situ diffraction } & \text { Krist.docx } & \\ \begin{array}{l}\text { Hansen2, Daniel Maria } \\ \text { Többens3, Holger }\end{array} & & & \\ \text { Kohlmann1* } & & & \end{array}$


fact of the refinement and this phase might show no homogeneity range or only a small one in contrast to $\beta$ -

$\mathrm{SrGeH}_{\mathrm{y}} \cdot[20]$

Above $400 \mathrm{~K}, \alpha-\mathrm{BaGeD}_{\mathrm{y}}$ is formed starting with $\mathrm{y}=0.32(3)(b / c=2.94$, cf. Tab. 3). During the heating process, deuterium is slowly released going down to $\mathrm{y}=$ $0.167(10)(b / c=2.87$, cf. Tab. 3) at the maximum temperature of $450 \mathrm{~K}$. Rietveld refinement after cooling down to $325 \mathrm{~K}$ showed a composition $\alpha-\mathrm{BaGeD}_{0.131(5)}$.

Under isothermic conditions at $502 \mathrm{~K}$ the deuterium pressure was cycled between vacuum $(10 \mathrm{~Pa})$ and 0.2 MPa. Diffraction patterns were collected with $10 \mathrm{~s}$ time resolution. To improve counting statistics, the experiment was repeated five times and diffraction patterns of equal pressure conditions were summed (Fig. 10). Starting from $\alpha-\mathrm{BaGeD}_{\mathrm{y}}$, the $\beta$-phase was allowed to form for $2 \mathrm{~min}$ at $0.2 \mathrm{MPa}$ to have the same starting conditions for each repetition.

The reaction from $\beta$ - to $\alpha-\mathrm{BaGeD}_{\mathrm{y}}$ is fully reversible and only depends on the applied pressure. On this time scale the occupation of the tetrahedral voids stays constant (Fig. 10). The D1 site of the $\beta$-phase shows an occupation of 0.90(4) averaged over the whole experiment except for the points with less than $25 \%$ phase content. The occupation of the empty D2 site was refined as well and shows no additional deuterium incorporation (averaged $\mathrm{SOF}=$ $0.029(13))$.

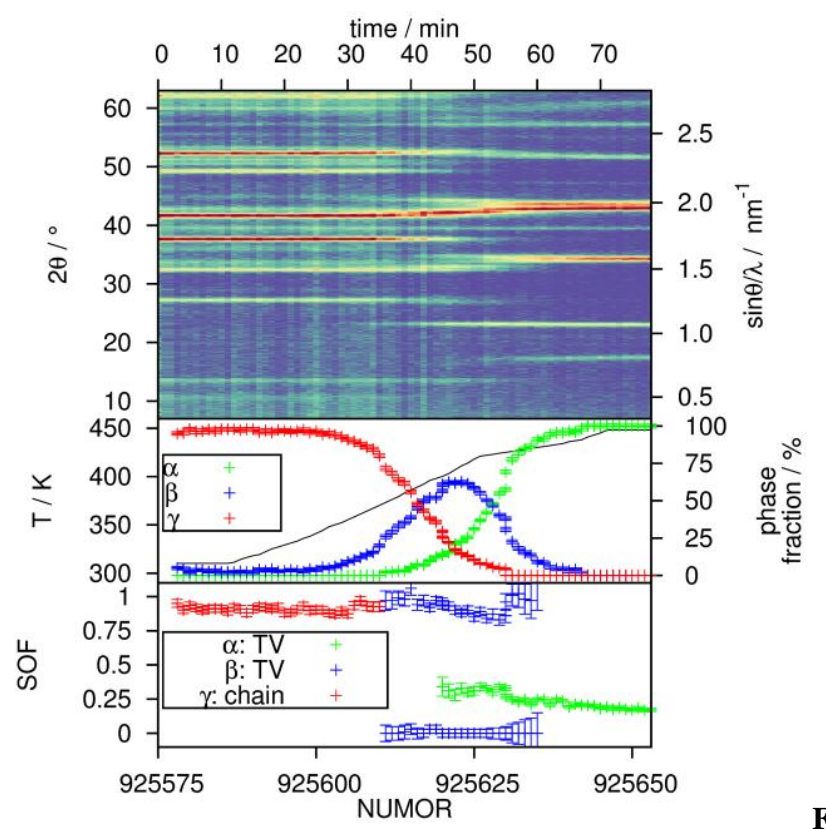

ig. 9. 2D diffraction plot of the decomposition of in situ formed $\gamma$ $\mathrm{BaGeD}_{1.61}$ under primary vacuum (top), temperature and phase fraction profiles (middle) and deuterium site occupation factors (SOF, bottom). $\gamma$-BaGeDy: sum of the split position of the chain binding sites (chain); $\alpha$ - and $\beta-\mathrm{BaGeD}_{\mathrm{y}}$ : tetrahedral voids (TV). ILL raw data labelling (NUMOR) is given [27]. 


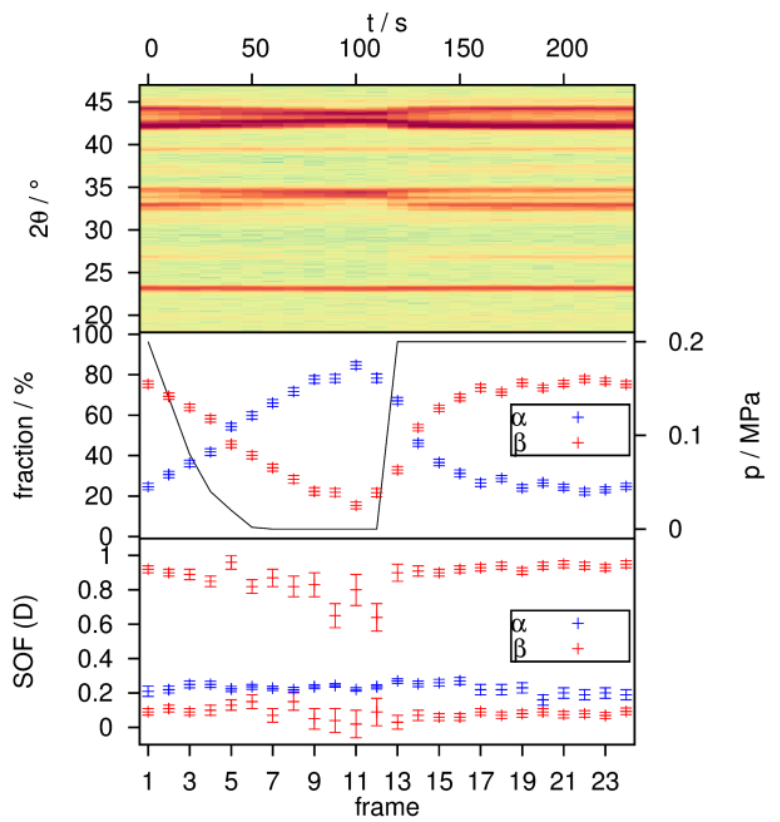

Fig. 10. Pressure dependent cyclic formation of $\alpha$ - (primary vacuum) and $\beta-\mathrm{BaGeD}_{\mathrm{y}}\left(0.2 \mathrm{MPa} \mathrm{D}_{2}\right)$ at isothermal conditions at $502 \mathrm{~K}$ (top), pressure and phase fraction profiles (middle) and deuterium site occupation factors (SOF) of tetrahedral voids (bottom). ILL raw data labelling (NUMOR) is given [27].

$\alpha-\mathrm{BaGeD}_{\mathrm{y}}$ shows a constant deuterium occupation on this time scale (averaged SOF $=0.23(2)$ ). A hint pointing towards a phase width is a small volume jump of $0.6 \%$ when the sample is pressurized. The $b / c$ ratio decreases during evacuation from 2.94 to 2.90 and jumps back to 2.95 when the sample is pressurized with deuterium to $0.2 \mathrm{MPa}$. The volume of $\beta-\mathrm{BaGeD}_{\mathrm{y}}$ is not effected at all $(<0.1 \%$ volume change). After a further dehydrogenation under vacuum for 30 min, a composition of $\alpha-\mathrm{BaGeD}_{0.095(7)}$ was reached, clearly indicating a homogeneity range of this phase.

\section{In situ neutron diffraction of BaSn}

In situ neutron diffraction of $\mathrm{BaSn}$ was done under 5.0(1) MPa isobaric deuterium pressure and heating. Diffraction patterns were collected with 1 min time resolution. For serial Rietveld refinement a summation over five frames was applied. The orientation of the single-crystal cell was inadequate and needed correction. Due to this technical issue the experiment was interrupted for about $100 \mathrm{~min}$ at elevated temperatures. After the correction some container reflections were still present. Furthermore, a significant fraction of $\gamma-\mathrm{BaSnD}_{\mathrm{y}}$ was already formed. Due to severe overlap with $\gamma-\mathrm{BaSnD}_{\mathrm{y}}$ and the broadness of the reflections the formation of $\alpha-\mathrm{BaSnD}_{\mathrm{y}}$ at low temperatures cannot be evaluated unambiguously. Therefore, sequential Rietveld refinement results are shown, starting with the decomposition of $\gamma-\mathrm{BaSnD}_{\mathrm{y}}$ (Fig. 11). At $423 \mathrm{~K}$ the decomposition of $\gamma-\mathrm{BaSnD}_{\mathrm{y}}$ starts, which is well below the endothermic DSC signal at $500 \mathrm{~K}$. The reformation of the $\gamma$-phase is reversible without hysteresis and the phase fraction starts to increase again after the temperature was below

Author

Henry Auer1, Sebastian

Weber1, Thomas Christian

Hansen2, Daniel Maria

Többens3, Holger

Kohlmann 1*
Title

Reversible hydrogenation of the Zintl phases BaGe and BaSn studied by in situ diffraction
File Name

zintl_B2_Z Krist.docx
Date

19.12.2017
Page 15 (20) 
$423 \mathrm{~K}$. The reformation step fits to the exothermic signal obtained in the DSC experiment.

The structure of $\gamma-\mathrm{BaSnD}_{\mathrm{y}}$ was kept fixed during the serial refinement and only the occupation of the tin binding deuterium site was refined. Considering estimated standard uncertainties (e.s.u.). this value stays constant over the whole experiment. The first formation leads to an averaged chemical formula $\gamma-\mathrm{BaSnD}_{\mathrm{y}}, \mathrm{y}=1.273(13)$. The reformation during the cooling process results in a slightly larger value of $y=1.291(3)$. Both evaluations fit the published value $y=1.278(2)$ [21] reasonably well. Thus, no homogeneity range is assumed here.

Starting with the decomposition of $\gamma-\mathrm{BaSnD}_{\mathrm{y}}$, the $\alpha-\mathrm{BaSnD}_{\mathrm{y}}$ is present during the rest of the experiment. The deuterium occupation is sensitive to temperature. It goes down to $\mathrm{y}=0.172(4)(b / c=2.78)$ at the highest measured temperature of 519(2) K. Right after the $\gamma$-phase started to decompose $(430(2) \mathrm{K})$ about one quarter of the tetrahedral voids is filled ( $\mathrm{y}=0.260(8) ; b / c=2.80)$. This value is reached again upon cooling $(430(2) \mathrm{K}, \mathrm{y}=0.248(4), b / c=$ 2.80). After the reformation of $\gamma-\mathrm{BaSnH}_{\mathrm{y}}$, at the end of the in situ experiment the $\alpha$-phase is still present with 31(2) wt$\%$ and reaches a maximum deuterium occupation of $\mathrm{y}=$ $0.36(3)(317(2) \mathrm{K}, b / c=2.81)$ The formation of a $\beta$-phase was not observed.

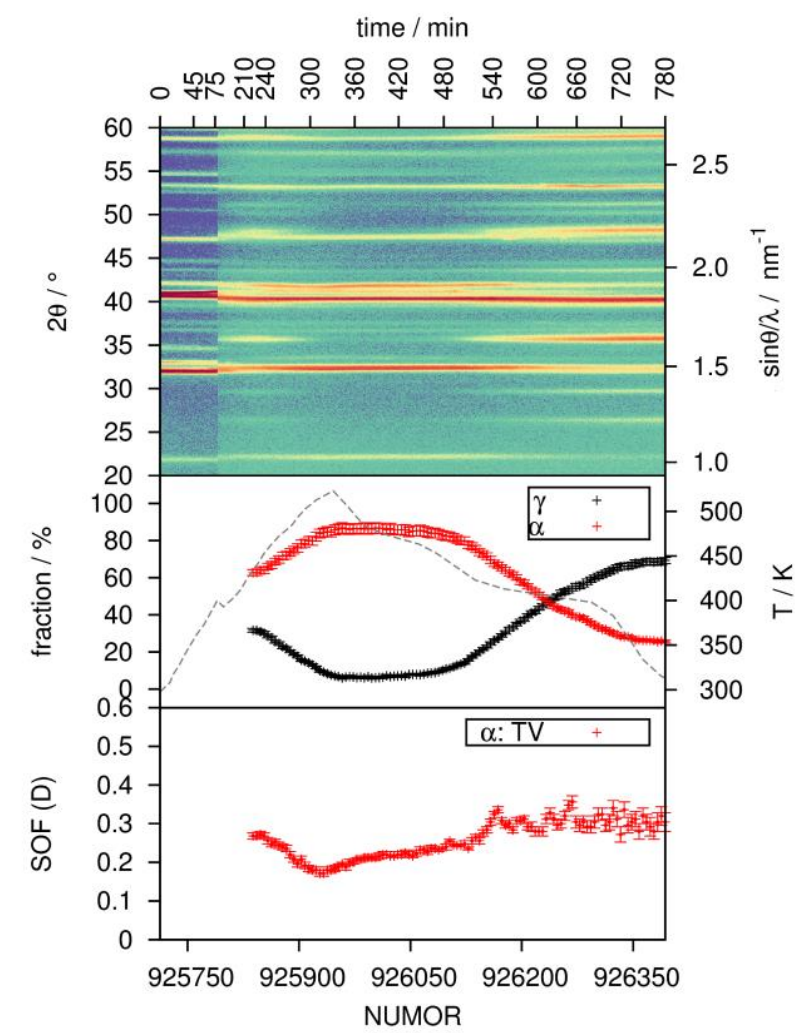

Fig. 11. 2D in situ diffraction plot of the reaction of BaSn at 5 $\mathrm{MPa} \mathrm{D}_{2}$ pressure (top), temperature and phase fractions (middle) and deuterium site occupation factors (SOF) of tetrahedral voids (TV, bottom). SOF(D) of $\gamma$-BaSnDy (chain-binding and TV) are constant (not shown). Due to technical issues (see text) the evaluation starts at $t=200 \mathrm{~min}$. ILL raw data labelling (NUMOR) is given [27]. 


\section{Conclusions}

The formation and decomposition of different types of BaTt $\mathrm{H}_{\mathrm{y}}$-phases, $T t=\mathrm{Ge}$, Sn, were observed by in situ diffraction and thermal analysis under several conditions. It could be shown that another two representatives of the system AeTt $-\mathrm{H}_{2}$ show almost reversible hydrogenation properties. Upon decomposition under pressure as well as under vacuum some residual hydrogen stays in tetrahedral voids forming $\alpha-B a T t \mathrm{H}_{\mathrm{y}}$ phases. These show a homogeneity range and a hydrogen occupation sensitive to pressure and temperature. This contribution establishes compositional limits for $\alpha-\mathrm{BaGeH}_{\mathrm{y}}$ of at least $0.095(7) \leq \mathrm{y} \leq 0.32(3)$ and for $\alpha-\mathrm{BaSnH}_{\mathrm{y}}$ of at least $0.172(4) \leq \mathrm{y} \leq 0.36(3)$.

The $\alpha$-phases show slightly shorter $T t$-Tt distances than the hydrogen free phases due to a depopulation of $\pi^{*}$ bands and, therefore increased $\pi$-bonding within zigzag chains. This correlates well with the electron poor CrBstructure type phase $\mathrm{Na}_{0.14} \mathrm{Sr}_{0.86} \mathrm{Ge}$ [40] or $\alpha-\mathrm{SrGeH}_{\mathrm{y}}, \mathrm{y}<$ $0.3,[20,23]$ which have a similar electron count per anion.

Another intermediate phase exists in the $\mathrm{BaGe}-\mathrm{H}_{2}$ system, which can be related to the $\mathrm{SrGe}-\mathrm{H}_{2}$ system [20]. In contrast to $\beta-\mathrm{SrGeH}_{\mathrm{y}}, \beta-\mathrm{BaGeH}_{0.5}$ appears to be a line phase with ordered hydrogen occupation. It already appears at room temperature, when $\mathrm{BaGe}$ is set under hydrogen pressure and is a decomposition product of $\gamma-\mathrm{BaGeH}_{\mathrm{y}}$ at elevated temperature. Due to stronger oxidation compared to the $\alpha$-phase, $\beta$ - $\mathrm{BaGeH}_{0.5}$ shows stronger $\pi$-bonding and thus decreased Ge-Ge distance. Therefore, the phase can be related to $\mathrm{Li}_{4} \mathrm{Ge}_{2} \mathrm{H}[44,45]$. Switching between $0.2 \mathrm{MPa} \mathrm{D}_{2}$ pressure and primary vacuum $(10 \mathrm{~Pa})$ at $500 \mathrm{~K}$ the formation of $\alpha$ - and $\beta-\mathrm{BaGeD}_{\mathrm{y}}$ can be cycled. At $2 \mathrm{MPa}$ the uptake is fast and $\alpha-\mathrm{BaGeD}_{\mathrm{y}}$ reacts almost completely to form $\beta-\mathrm{BaGeD}_{0.5}$ within $1 \mathrm{~min}$. The corresponding deuterium release is slower.

Upon heating to moderate temperatures $(<400 \mathrm{~K})$ and hydrogen pressures above $3 \mathrm{MPa}, \mathrm{BaGe}$ and $\mathrm{BaSn}$ form hydrogen rich $\gamma$-phases as published earlier [21, 22]. These phases are characterised by ionic hydride ions that are incorporated into sheets of tetrahedral $\mathrm{Ba}_{4}$-voids and hydrogen bound covalently to the polyanion.

The formation of $\gamma$-phases can be rationalised using a hypothetical intermediate $\mathrm{BaTt} \mathrm{H}$, where according to the Zintl-Klemm concept $T t$ is supposed to form threebinding polyanions. Due to the rigid hydride filled cationic sheets, the $T t^{-}$atoms cannot solely form bonds to other $T t^{-}$ ions but need to additionally form $T t$-H bonds (see Fig. 2e). Filling tetrahedral voids is thus directly related to the formation of $T t-\mathrm{H}$ bonds and vice versa. Since Ge-H and $\mathrm{Sn}-\mathrm{H}$ bonds are thermally labile, the $\gamma$-phases decompose at moderate temperatures under vacuum or $5 \mathrm{MPa}$ hydrogen pressure and need to release additional hydrogen from tetrahedral $\mathrm{Ba}_{4}$-sites. The decomposition temperatures fit the thermal decomposition of polygermane $\left(\mathrm{GeH}_{\mathrm{y}}\right)_{\infty}$ at 470 $520 \mathrm{~K}$ [46] reasonably well. Therefore these phases show a good (partial) reversibility relating them to classical interstitial hydrides combined with moderate decomposition temperatures due to thermally labile $T t-\mathrm{H}$ bonds. In addition to the almost complete reversibility the filling of tetrahedral voids shows fast kinetics as shown by the reaction of $\alpha$ - to

$\begin{array}{llll}\text { Author } & \text { Title } & \text { File Name } & \text { Date } \\ \text { Henry Auer1, Sebastian } & \text { Reversible hydrogenation of the Zintl phases BaGe and BaSn studied } & \text { zintl_B2_Z- } & \text { 19.12.2017 } \\ \text { Weber1, Thomas Christian } & \text { by in situ diffraction } & 17 \text { (20) } \\ \text { Hansen2, Daniel Maria } & & \\ \text { Többens3, Holger } & & \\ \text { Kohlmann1* } & & \end{array}$


$\beta-\mathrm{BaGeH}_{\mathrm{y}}$. This might serve as a starting point for the search of proper hydrogen storage systems within the class of Zintl phases.

\section{Acknowledgements}

We thank the Institute Laue-Langevin (ILL) for providing neutron (proposal 5-22-734) and the Helmholtz Zentrum Berlin (HZB) for providing synchrotron beam time (proposal 15202481). Furthermore, we want to thank Dr. Dirk Wallacher and Nico Grimm for set up and support with the in situ experiment at BESSY II. We thank the Deutsche Forschungsgemeinschaft (DFG, grant Ko1803/8-1) and the Fonds der Chemischen Industrie (Grant 194371) for financial support.

\section{References}

[1] M. Aoki, N. Ohba, T. Noritake, S. Towata, Reversible hydriding and dehydriding properties of CaSi: Potential of metal silicides for hydrogen storage, Appl. Phys. Lett., 2004, 85, 387388.

[2] N. Ohba, M. Aoki, T. Noritake, K. Miwa, S. Towata, Firstprinciples study of a hydrogen storage material CaSi, Phys. Rev. $B, 2005,72,075104$.

[3] J.-N. Chotard, W. S. Tang, P. Raybaud and R. Janot, Potassium Silanide $\left(\mathrm{KSiH}_{3}\right)$ : A Reversible Hydrogen Storage Material, Chem. - Eur. J.,2011, 17, 12302-12309.

[4] J. Zhang, S. Yan, H. Qu, X. Yu, P. Peng, Alkali metal silanides $\alpha$-MSiH3: A family of complex hydrides for solid-state hydrogen storage, Int. J. Hydrogen Energy, 2017, 42, 12405-12413.

[5] F. Gingl, T. Vogt, E. Akiba, Trigonal $\mathrm{SrAl}_{2} \mathrm{H}_{2}$ : the first Zintl phase hydride, J. Alloys Compd., 2000, 306, 127-132.

[6] Y. Zhu, W. Zhang, Z. Liu, L. Li, Hydrogen storage properties of the Zintl phase alloy $\mathrm{SrAl}_{2}$ doped with $\mathrm{TiF}_{3}$, J. Alloys Compd., 2010, 492, 277-281.

[7] S. Orimo, Y. Nakamori, J. R. Eliseo, A. Züttel, C. M. Jensen, Complex Hydrides for Hydrogen Storage, Chem. Rev., 2007, 107, 4111-4132.

[8] F.H. Stephens, V. Pons, R. T. Baker, Ammonia-borane: the hydrogen source par excellence?, Dalton Trans., 2007, 2613-2626. [9] B. Sakintuna, F. Lamari-Darkrim, M. Hirscher, Int. J. Hydrogen Energy, 2007, 32, 1121-1140.

[10] I. Jain, C: Lal, A. Jain, Hydrogen storage in Mg: A most promising material, Int. J. Hydrogen Energy, 2010, 35, 5133 5144.

[11] N. Rusman, M. Dahari, A review on the current progress of metal hydrides material for solid-state hydrogen storage applications, Int. J. Hydrogen Energy, 2016, 41, 12108-12126. [12] H. Wang, H. Lin, W. Cai, L. Ouyang, M. Zhu, Tuning kinetics and thermodynamics of hydrogen storage in light metal element based systems - A review of recent progress, J. Alloys Compd., 2016, 658, 280-300.

[13] U. Häussermann, V. F. Kranak, K. Puhakainen, Hydrogenous Zintl Phases: Interstitial Versus Polyanionic Hydrides, Struct. Bond., 2010, 139, 143-161.

[14] T. C. Hansen, H. Kohlmann, Chemical Reactions followed by in situ Neutron Powder Diffraction, Z. Anorg. Allg. Chem., 2014, 640, 3044-3063.

[15] K. T. Möller, B. R. S. Hansen, A.-C. Dippel, J.-E. Jørgensen, T. R. Jensen, Characterization of Gas-Solid Reactions using In Situ Powder X-ray Diffraction, Z. Anorg. Allg. Chem., 2014, 640, 3029-3043. 
[16] D. J. Bull, E. Weidner, I. L. Shabalin, M. T. F. Telling, C. M. Jewell, D. H. Gregory, D. K Ross, Pressure-dependent deuterium reaction pathways in the Li-N-D system, Phys. Chem. Chem. Phys., 2010, 12, 2089-2097.

[17] G. Behrendt, C. Reichert, H. Kohlmann, Hydrogenation Reaction Pathways in the Systems $\mathrm{Li}_{3} \mathrm{~N}-\mathrm{H}_{2}, \mathrm{Li}_{3} \mathrm{~N}-\mathrm{Mg}-\mathrm{H}_{2}$, and $\mathrm{Li}_{3} \mathrm{~N}-\mathrm{MgH}_{2}-\mathrm{H}_{2}$ by in Situ X-ray Diffraction, in Situ Neutron Diffraction, and in Situ Thermal Analysis, J. Phys. Chem. C, 2016, 120, 13450-13455.

[18] P. Wenderoth, H Kohlmann, In Situ Neutron Powder Diffraction of the Formation of $\mathrm{SrGa}_{2} \mathrm{D}_{2}$, and Hydrogenation Behavior of $\mathrm{YbGa}_{2}$ and $\mathrm{EuGa}_{2}$, Inorg. Chem., 2013, 52, 1052510531.

[19] H. Auer, H. Kohlmann, In situ Investigations on the Formation and Decomposition of $\mathrm{KSiH}_{3}$ and $\mathrm{CsSiH}_{3}$, Z. Anorg. Allg. Chem., 2017, 643, 945-951.

[20] H. Auer, D. Wallacher, T. C. Hansen, H. Kohlmann, In Situ Hydrogenation of the Zintl Phase SrGe, Inorg. Chem., 2017, 56, 1072-1079.

[21] H. Auer, R. Guehne, M. Bertmer, S. Weber, P. Wenderoth, T. C. Hansen, J. Haase, H. Kohlmann, Hydrides of Alkaline EarthTetrel (AeTt) Zintl Phases: Covalent Tt-H Bonds from Silicon to Tin, Inorg. Chem., 2017, 56, 1061-1071.

[22] H. Auer, R. Schlegel, O. Oeckler, H. Kohlmann, Structural and Electronic Flexibility in Hydrides of Zintl Phases with TetrelHydrogen and Tetrel-Tetrel Bonds, Angew. Chem., Int. Ed., 2017, 56, 12344-12347; H. Auer, R. Schlegel, O. Oeckler, H.

Kohlmann, Strukturelle und elektronische Flexibilität in Hydriden von Zintl-Phasen mit Tetrel-Wasserstoff- und Tetrel-TetrelBindung, Angew. Chem., 2017, 129, 12515-12518.

[23] A. Götze, H. Auer, R. Finger, T. C. Hansen, H. Kohlmann, A sapphire single-crystal cell for in situ neutron powder diffraction of solid-gas reactions, Phys. B, 2017, DOI:

10.1016/j.physb.2017.11.024.

[24] Helmholtz-Zentrum Berlin für Materialien und Energie, KMC-2: an X-ray beamline with dedicated diffraction and XAS endstations at BESSY II, Journal of large-scale research facilities, 2016, 2, A49.

[25] T. C. Hansen, P. F. Henry, H. E. Fischer, J. Torregrossa, P. Convert, The D20 instrument at the ILL: a versatile high-intensity two-axis neutron diffractometer, Meas. Sci. Technol., 2008, 19, 034001 .

[26] H. Kohlmann, N. Kurtzemann, R. Weihrich, T. Hansen, In situ Neutron Powder Diffraction on Intermediate Hydrides of $\mathrm{MgPd}_{3}$ in a Novel Sapphire Gas Pressure Cell, Z. Anorg. Allg. Chem., 2009, 635, 2399-2405.

[27] H. Kohlmann, H. Auer, A. Götze, T. Hansen, S. Weber, Reaction pathways to the Zintl phase hydrides $\mathrm{CaSiH}$ and $\mathrm{MGeH}_{\mathrm{x}}$ ( $\mathrm{M}=\mathrm{Sr}, \mathrm{Ba})$, Institut Laue-Langevin (ILL), 2015,

doi:10.5291/ILL-DATA.5-22-734.

[28] H. M. Rietveld, Line profiles of neutron powder-diffraction peaks for structure refinement, Acta Crystallogr., 1967, 22, 151152.

[29] H. M. Rietveld, A profile refinement method for nuclear and magnetic structures, J. Appl. Crystallogr., 1969, 2, 65-71.

[30] J. Rodriguez-Carvajal, Recent advances in magnetic structure determination by neutron powder diffraction, Phys. B, 1993, 192,

$55-69$.

[31] FullProf.2k, Version 5.30 - Mar2012-ILL JRC.

[32] Bruker AXS, TOPAS version 5, www.bruker-axs.com.

[33] K. Momma \& F. Izumi, VESTA3 for three-dimensional visualization of crystal, volumetric and morphology data, J. Appl.

Crystallogr., 2011, 44, 1272-1276.

[34] VESTA - Visualisation for Electronic and STructural

Analysis, version 3.3.1.

Author

Henry Auer1, Sebastian

Weber1, Thomas Christian

Hansen2, Daniel Maria

Többens3, Holger

Kohlmann $1 *$
Title

Reversible hydrogenation of the Zintl phases BaGe and BaSn studied by in situ diffraction
File Name

zintl_B2_Z Krist.docx
Date

19.12.2017
Page 19 (20) 
[35] L. M. Gelato, E. Parthé, STRUCTURE TIDY - a computer program to standardize crystal structure data, J. Appl. Crystallogr., 1987, 20, 139-143.

[36] E. C. Reyes, E. D. Stalder, C. Mensing, S. Budnyk, R.

Nesper, Unexpected Magnetism in Alkaline Earth Monosilicides, J. Phys. Chem. C, 2011, 115, 1090-1095.

[37] E. C. Reyes, R. Nesper, Electronic Structure and Properties of the Alkaline Earth Monosilicides, J. Phys. Chem. C, 2012, 116, 2536-2542.

[38] I. M. Kurylyshyn, T. F. Fässler, A. Fischer, C. Hauf, G. Eickerling, M. Presnitz, W. Scherer, Probing the Zintl-Klemm Concept: A Combined Experimental and Theoretical Charge Density Study of the Zintl Phase CaSi, Angew. Chem., Int. Ed., 2014, 53, 3029-3032.

[39] W. Harms, M. Wendorff, C. Röhr, Structure and bonding of ternary gallides $\mathrm{CaGa}_{1-\mathrm{x}}(\mathrm{Si} / \mathrm{Sn} / \mathrm{Al} / \mathrm{In})_{\mathrm{x}}$ with the $\mathrm{CrB}$ type and related structures, J. Alloys Compd., 2009, 469, 89-101.

[40] Q.-X.Xie, R. Nesper, Crystal structure of sodium strontium monogermanide, $\mathrm{Na}_{x} \mathrm{Sr}_{1-\mathrm{x}} \mathrm{Ge}(\mathrm{x}=0.14), Z$. Kristallogr. - New Cryst. Struct., 2003, 218, 291-292.

[41] Further details of the crystal structure investigations may be obtained from FIZ Karlsruhe, 76344 Eggenstein-Leopoldshafen, Germany (fax: (+49)7247-808-666; e-mail: crysdata(at)fizkarlsruhe(dot)de, on quoting the deposition numbers CSD-433794 $\left(\alpha-\mathrm{BaGeD}_{0.09}\right), \mathrm{CSD}-433795\left(\alpha-\mathrm{BaGeD}_{0.13}\right), \mathrm{CSD}-433796(\alpha-$ $\left.\mathrm{BaSnD}_{0.19}\right)$, CSD-433797 ( $\left.\beta-\mathrm{BaGeD}_{0.49}\right)$.

[42] V. P. Ting, P. F. Henry, H. Kohlmann, C. C. Wilson, M. T. Weller, Phys. Chem. Chem. Phys. 2010, 12, 2083-2088.

[43] H. Bärnighausen, Group-Subgroup realtions between space groups: a useful tool in crystal chemistry, MATCH: Commun. Math. Comput. Chem., 1980, 9, 139-175.

[44] H. Wu, W. Zhou, T. J. Udovic, J. J. Rush, T. Yildirim, M. R. Hartman, R. C. Bowman, J. J. Vajo, Neutron vibrational spectroscopy and first-principles calculations of the ternary hydrides $\mathrm{Li}_{4} \mathrm{Si} 2 \mathrm{H}(\mathrm{D})$ and $\mathrm{Li}_{4} \mathrm{Ge}_{2} \mathrm{H}(\mathrm{D})$ : Electronic structure and lattice dynamics, Phys. Rev. B, 2007, 76, 224301.

[45] H. Wu, M. R. Hartman, T. J. Udovic, J. J. Rush, W. Zhou, R. C. Bowman Jr, J. J. Vajo, Structure of the novel ternary hydrides $\mathrm{Li}_{4} \mathrm{Tt}_{2} \mathrm{D}(\mathrm{Tt}=\mathrm{Si}$ and Ge), Acta Crystallogr., Sect. B, 2007, 63, 6368.

[46] E. Bianco, S. Butler, S. Jiang, O. D. Restrepo, W. Windl, J.

E. Goldberger, Stability and Exfoliation of Germanane: A

Germanium Graphane Analogue, ACS Nano, 2013, 7, 4414-4421. 